\title{
Heuristic optimization of prestressed concrete precast pedestrian bridges
}

\author{
J. V. Martí, F. González-Vidosa \& J. Alcalá \\ School of Civil Engineering, Universidad Politécnica Valencia, Spain
}

\begin{abstract}
This paper deals with the economic optimization of prestressed concrete precast pedestrian bridges typically used in public works construction. These bridges are made of a precast concrete beam that integrates an upper reinforced concrete slab for the pedestrian traffic. The beam has a U-shape cross-section. Typical span lengths range from 20 to $40 \mathrm{~m}$ and the width ranges from 3.00 to $6.00 \mathrm{~m}$. The study shows the efficiency of heuristic optimization by the simulated annealing (SA) and the threshold accepting (TA) algorithms. The evaluation of solutions follows the Spanish Code for structural concrete. Stress resultants and envelopes of these structures are computed by direct calculation. Design loads are in accordance with the national IAP Code for road bridges. The algorithms are applied to a typical pedestrian bridge of $40 \mathrm{~m}$ of span length and $6.00 \mathrm{~m}$ of width. This example has 59 discrete design variables for the geometry of the beam and the slab, materials in the two elements and active and passive reinforcement. The evaluation module includes the limit states that are commonly checked in design: flexure, shear, deflections, etc. The application of the SA and TA algorithms requires the calibration of the initial temperature and threshold, the number of variables modified in each iteration, the length of the Markov chains and the reducing coefficient. Each heuristic is run nine times so as to obtain statistical information about the minimum, average and deviation of the results. The best result has a cost of 27,586 euros for the SA algorithm and 27,570 euros for the TA algorithm. Finally, solutions and run times indicate that heuristic optimization is a forthcoming option for the design of real prestressed structures.
\end{abstract}

Keywords: economic optimization, heuristics, concrete structures, structural design. 


\section{Introduction}

Artificial intelligence has dealt, since its appearance in the mid-fifties, with a variety of fields, such as automatic programming, the solution of constrained problems, operational research, planning, neuronal networks, etc. The design of structures is a problem of selection of design variables subject to structural constraints for which artificial intelligence is very much suited. Design variables include material grades, cross section dimensions and reinforcement. In spite of the potential capabilities of artificial intelligence, the present design of economic concrete structures is much conditioned by the experience of structural engineers. The traditional design of concrete structures aims at producing safe structures that sustain the loads and deformations, as well as the durability conditions of their intended life [1]. Also traditionally, designs have usually been based on the prior experience of the structural engineer, which has derived in a number of rules of thumb about cross-section dimensions and material grades based on sanctioned common practice. Once the structure is defined, it follows the analysis of stress resultants and the computation of passive and active reinforcement that satisfy the limit states prescribed by concrete codes. Should the dimensions or material grades be insufficient, the structure is redefined on a trial and error basis. Such process leads to safe designs, but the economy of the concrete structures is, therefore, very much linked to the experience of the structural designer.

Optimization methods deal with the minimization of the objective function, which is usually the cost or the weight of the structure. In addition, multiobjective optimization algorithms offer a range of possibilities about the study of two or several conflicting objectives. As regards concrete structures, there have been few applications when compared to steel structures [2]. In general terms, the methods of structural optimization may be classified into two broad groups: exact methods and heuristic methods. The exact methods are the traditional approach. They are usually based on the calculation of optimal solutions following iterative techniques of linear programming [3,4]. The second main group are the heuristic methods, whose recent development is linked to the evolution of artificial intelligence procedures. This group includes a broad number of search algorithms [5-8], such as genetic algorithms, simulated annealing, threshold accepting, tabu search, ant colonies, etc. These methods have been successful in areas different to structural engineering [9]. They consist of simple algorithms, but require a great computational effort, since they include a large number of iterations in which the objective function is evaluated and the structural constraints are checked. Among the first works of heuristic optimization applied to steel structures, the contributions of Jenkins and of Rajeev and Krishnamoorthy in 1992 are to be mentioned [10,11]. Both studies applied genetic algorithms to the optimization of the weight of steel structures. Regarding reinforced concrete (RC) structures, early applications in 1997 include the work of Coello et al [12], who applied genetic algorithms to the economic optimization of RC beams. Recently, there have been a number of RC applications [13-20], which optimize RC beams and building frames by genetic 
algorithms. Also recently, our research group has applied simulated annealing and threshold acceptance to the optimization of walls, frame bridges, building frames, vaults and bridge piers [21-25].

The structures object of this work are prestressed concrete (PC) precast pedestrian bridges typically used in public works construction. These bridges are made of a precast concrete beam that integrates an upper reinforced concrete slab for the pedestrian traffic (Figure 1). The beam has a U-shape cross-section. Typical span lengths range from 20 to $40 \mathrm{~m}$ and the width ranges from 3.00 to $6.00 \mathrm{~m}$. The method followed in this work has consisted first in the development of an evaluation computer module where dimensions, materials and steel reinforcement have been taken as variables. These modules compute the cost of a solution and check all the relevant limit states. Simulated annealing and threshold accepting are then used to search the solution space.

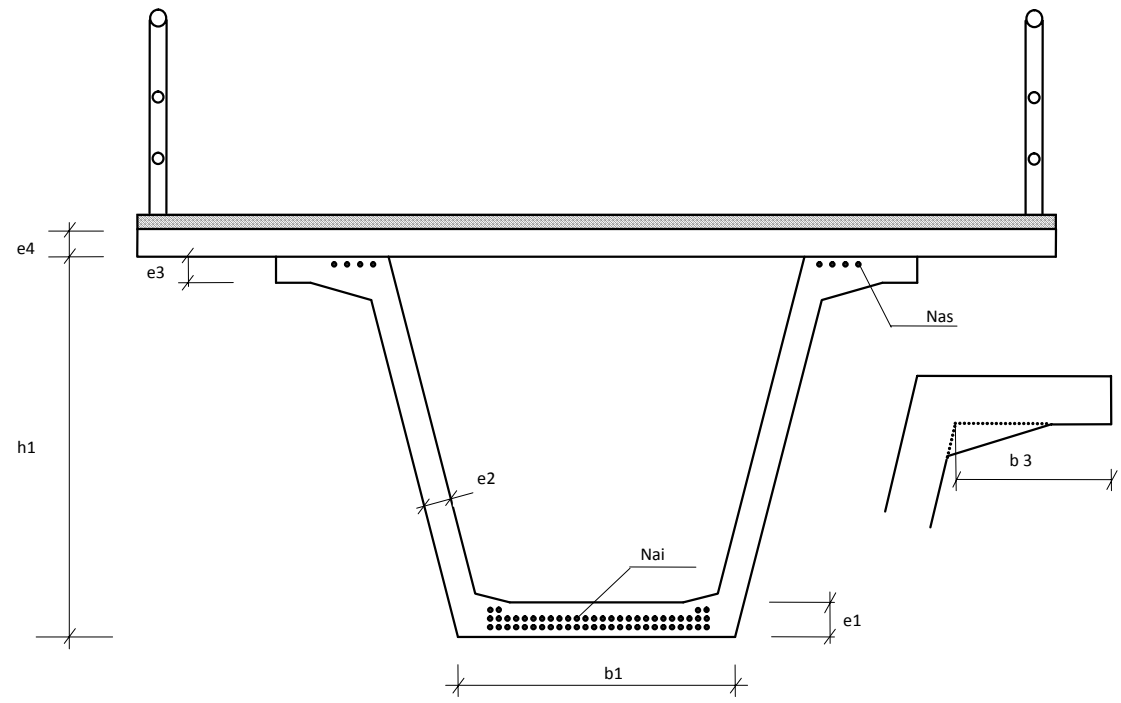

Figure 1: Geometric variables of the pedestrian PC precast bridge.

\section{Annealing and threshold optimization procedures}

The problem of structural concrete optimization that is put forward in the present work consists of an economic optimization. It deals with the minimization of the objective function $\mathrm{F}$ of expression (1), satisfying also the constraints of expressions (2).

$$
\begin{gathered}
F\left(x_{1}, x_{2}, \ldots x_{n}\right)=\sum_{i=1, r} p_{i} * m_{i}\left(x_{1}, x_{2}, \ldots, x_{n}\right) \\
g_{j}\left(x_{1}, x_{2}, \ldots . x_{n}\right) \leq 0
\end{gathered}
$$


Note that the objective function in expression (1) is the sum of unit prizes multiplied by the measurements of construction units (concrete, steel, formwork, etc). And that the constraints in expression (2) are all the service and ultimate limit states that the structure has to satisfy. Unit prizes considered are given in Table 1 .

Table 1: $\quad$ Basic prizes of the cost function of the reported structures.

\begin{tabular}{|l|r|r|}
\hline \multicolumn{1}{|c|}{ Description } & $\begin{array}{c}\text { Unit Price } \\
\text { in beam }(€)\end{array}$ & $\begin{array}{c}\text { Unit Price } \\
\text { in slab }(€)\end{array}$ \\
\hline Kg of passive steel (B-500-S) & 2.63 & 1.40 \\
\hline Kg of prestressing steel (Y-1860-S7) & 3.38 & NA \\
\hline m of formwork & 75.11 & NA \\
\hline $\mathrm{m}^{2}$ of lower formwork & NA & 30.00 \\
\hline $\mathrm{m}^{3}$ of concrete HA-25 & NA & 64.99 \\
\hline $\mathrm{m}^{3}$ of concrete HA-30 & NA & 69.95 \\
\hline $\mathrm{m}^{3}$ of concrete HA-35 & NA & 74.03 \\
\hline $\mathrm{m}^{3}$ of concrete HA-40 & 122.25 & 79.12 \\
\hline $\mathrm{m}^{3}$ of concrete HP-35 & 133.40 & NA \\
\hline $\mathrm{m}^{3}$ of concrete HP-40 & 142.15 & NA \\
\hline $\mathrm{m}^{3}$ of concrete HP-45 & 152.89 & NA \\
\hline $\mathrm{m}^{3}$ of concrete HP-50 & & \\
\hline
\end{tabular}

The first search method used in this work is the simulated annealing (SA henceforth), which was originally proposed by Kirkpatrick et al. [26] for the design of electronic circuits. The SA algorithm is based on the analogy of crystal formation from masses melted at high temperature and let cool slowly. At high temperatures, configurations of greater energy than previous ones may randomly form, but as the mass cools, the probability of higher energy configurations forming decreases. The algorithm starts with a feasible solution randomly generated and a high initial temperature. The initial working solution is changed by a small random move of the values of the variables. The new current solution is evaluated in terms of cost. Greater cost solutions are accepted when a 0 to 1 random number is smaller than the expression $\exp (-\Delta E / T)$, where $\Delta E$ is the cost increment and $T$ is the current temperature. The current solution is then checked against structural constraints and if it is feasible, it is adopted as the new working solution. The initial temperature is decreased geometrically $(T=k T)$ by means of a coefficient of cooling $k$. A number of iterations called Markov chains are allowed at each step of temperature. The algorithm stops when the temperature is a small percentage of the initial temperature or when there are no improvements in a number of Markov chains (typically 1\% or 1-2 Markov chains). The SA method is capable of surpassing local optima at high-medium temperatures and gradually converges as the temperature reduces to zero. The SA method requires calibration of the initial temperature, the length of the Markov chains and the cooling coefficient. Adopted values for this work will be given below. The initial temperature was adjusted following the method proposed by Medina [27], which 
consists in choosing an initial value and checking whether the percentage of acceptances of higher energy solutions is typically 20-40 percent. If the percentage is greater than $40 \%$, the initial temperature is halved; and if it is smaller than $20 \%$, the initial temperature is doubled. Computer runs were performed a number of times so as to obtain minimum, mean and other statistical data of the results.

The second search method used in this work is the threshold accepting (TA henceforth), that was originally proposed by Dueck and Scheuer [28]. The algorithm starts with an initial randomly generated working solution, $\mathrm{P}_{\mathrm{o}}$, and an initial high threshold value for accepting solutions. TA then changes the solution by a move. A move is a small random variation up or down to the values of some of the variables that define the current solution. Given a current solution, a move is applied and, hence, a new solution is obtained. The new current solution, $\mathrm{P}_{1}$, is accepted if it has a lower cost or when the cost increment is smaller than the current threshold value. The current solution is checked against structural constraints and if it is feasible, it is adopted as the new working solution $\mathrm{P}_{\mathrm{o}}$. The initial threshold is reduced geometrically and gradually by means of a reducing coefficient. A number of iterations at each threshold step are performed in the same way as for Markov chains of the simulated annealing method. TA method is capable of surpassing local optima and gradually converges as the threshold value reduces to zero. The method requires calibration of the initial threshold, of the length of the cycle chains and of the threshold-reducing coefficient. Adopted values for the two examples of this work will be given below. The initial threshold value was adjusted following the method proposed by Medina [27], which consists in choosing an initial value and checking whether the percentage of acceptances of higher cost solutions is typically between for instance 20-40 percent. If the percentage is greater than $40 \%$, the initial threshold is halved; and if it is smaller than $20 \%$, the initial threshold is doubled. Computer runs were performed 9 times so as to obtain minimum, mean and standard deviation of the random results.

\section{PC precast pedestrian bridge example}

The example studied relates to PC precast pedestrian bridges used in road construction [29]. The analysis includes 59 design variables. Fig. 1 shows the main geometrical variables considered in this analysis. Geometrical variables include 7 variables: the depth of the beam $\left(h_{1}\right)$, the thickness of the slab $\left(\mathrm{e}_{4}\right)$, the width of the soffit of the beam $\left(b_{1}\right)$ and the thickness of the bottom flange $\left(e_{1}\right)$, the width and thickness of the top flanges of the beam $\left(b_{3}\right.$ and $\left.e_{3}\right)$ and the thickness of the webs $\left(\mathrm{e}_{2}\right)$. Regarding material strength, 2 variables define the type of concrete of the slab and the beam. Prestressing is defined by 4 variables: the number of strands in the top flanges and the number of strands in the first, second and third layers of the bottom flange. Finally, 46 variables define a standard reinforcement set up for the beam and the top slab (Figure 2). All variables are discrete in this analysis. The total number of parameters is 15 , the most important of which are the free span, the width of the top slab, the 
inclination of the webs, the dead and live loads acting on the bridge, the type of active and passive reinforcing steel, the ambient conditions and the partial coefficients of safety. Structural constraints considered followed standard provisions for Spanish design of this type of structure [30,31], that include checks of the service and ultimate limit states of flexure and shear for the stress envelopes due to the self weight and the traffic loads. Traffic load considered is a uniform distributed load of $4 \mathrm{kN} / \mathrm{m}^{2}$. The dead load considered is a uniform distributed load of $2 \mathrm{kN} / \mathrm{m}^{2}$. Stress resultants and reactions were calculated by a stiffness matrix program using a 2-D mesh with 20 bars and 21 sections. Deflections were limited to $1 / 1000$ of the free span for the quasi-permanent combination. Fatigue of concrete and steel was not considered since this ultimate limit state is rarely checked in pedestrian bridges.

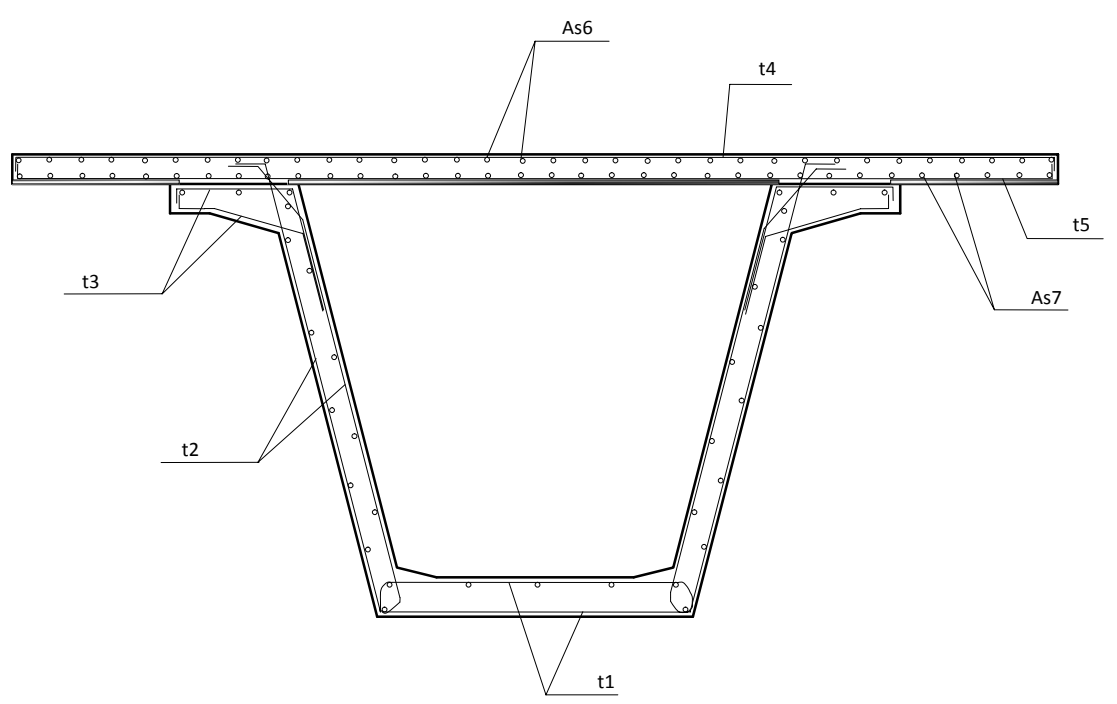

Figure 2: $\quad$ Passive reinforcement variables of the pedestrian bridge.

The SA-TA algorithms were programmed in Fortran 95 and applied to a pedestrian bridge of $40 \mathrm{~m}$ of span and a $6.00 \mathrm{~m}$ width. Typical SA-TA runs were about 25-15 minutes in an Intel Pentium IV processor of $3.00 \mathrm{GHz}$. The most efficient move found consisted of random variation of up to $10 \%$ of the 59 variables of the problem. The calibration of the simulated annealing parameters recommended Markov chains of 1000 iterations, a reducing coefficient of 0.95, an initial range of $40-60 \%$ of acceptances for the initial temperature and a stop criterion of $2 \%$ of the initial temperature and 2 chains without improvement. Figure 3 shows a typical evolution of the cost with the computing time for the SA algorithm. The minimum result has a cost of 27586.21 euros and the mean of the results is 29070.49 , the deviation with respect to the best being $5.38 \%$.

The calibration of threshold accepting parameters recommended chains of 500 iterations, a reducing coefficient of 0.95 , an initial range of $70-90 \%$ of 
acceptances for the initial threshold and a stop criterion of $2 \%$ of the initial threshold and 2 chains without improvement. Figure 4 shows a typical evolution of the cost with the computing time for the TA algorithm. The minimum result has a cost of 27570.17 euros and the mean of the results is 30378.42 , the deviation with respect to the best being $10.19 \%$.

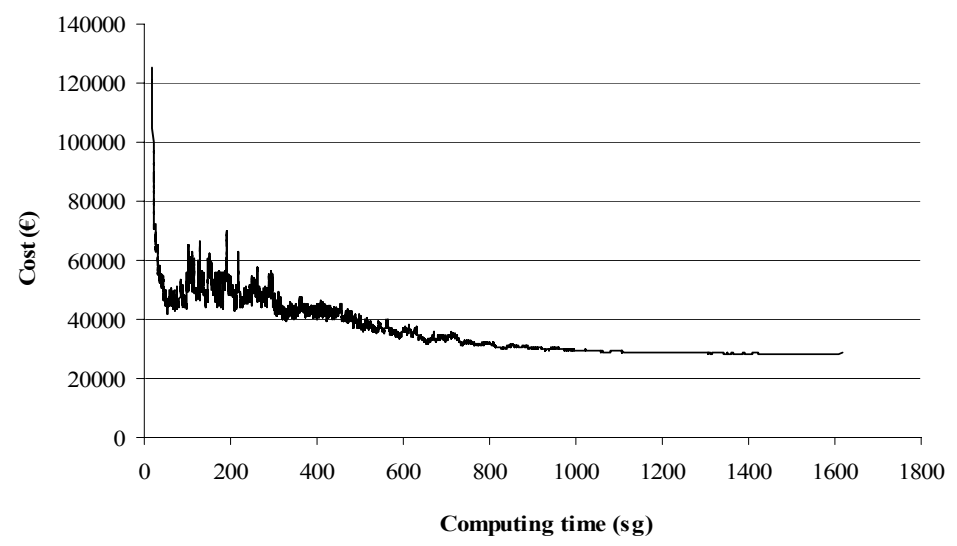

Figure 3: Typical cost evolution versus computing time for the SA algorithm.

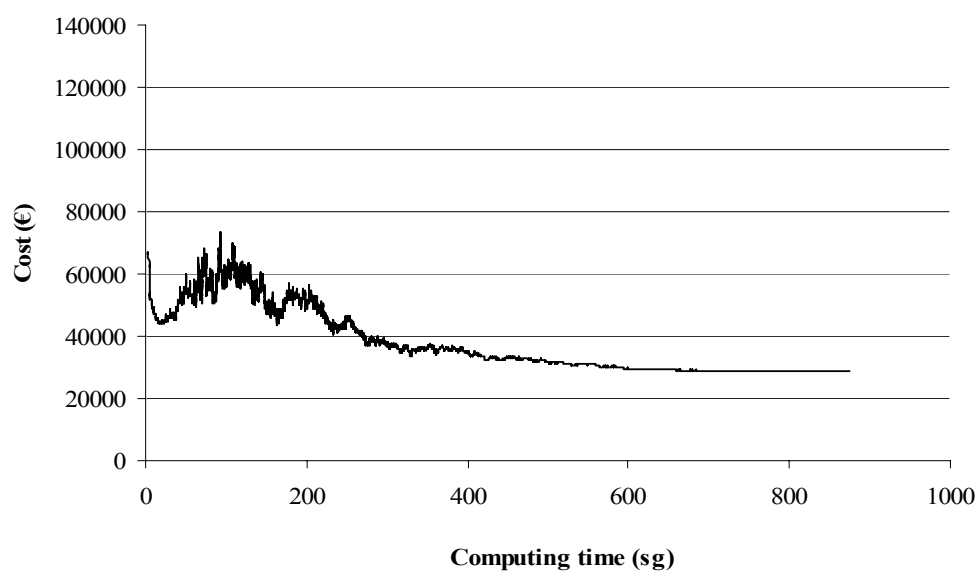

Figure 4: Typical cost evolution versus computing time for the TA algorithm.

It is worth noting that the SA algorithm outperforms the TA algorithm since it improves the deviation with respect to the best in the series of nine results.

Table 2 details the main results of the SA analysis for a pedestrian bridge of $40 \mathrm{~m}$ of span and a $6.00 \mathrm{~m}$ width. 
Table 2: $\quad$ Summary of best pedestrian bridge.

\begin{tabular}{|l|r|}
\hline \multicolumn{2}{|c|}{ Geometric variables } \\
\hline h1 & $2.950 \mathrm{~m}$ \\
\hline b1 & $1.180 \mathrm{~m}$ \\
\hline b3 & $0.240 \mathrm{~m}$ \\
\hline e1 & $0.150 \mathrm{~m}$ \\
\hline e2 & $0.100 \mathrm{~m}$ \\
\hline e3 & $0.180 \mathrm{~m}$ \\
\hline e4 & $0.125 \mathrm{~m}$ \\
\hline Nas & $6 \varnothing 0.6$ \\
\hline Nai & $29 ø 0.6$ \\
\hline \multicolumn{2}{|c|}{ Concrete grades } \\
\hline Beam & HA-35 \\
\hline Slab & HA-25 \\
\hline \multicolumn{1}{|c|}{ Reinforc. at support cross-section } \\
\hline As6 & $24 \varnothing 6$ \\
\hline As7 & $24 \varnothing 6$ \\
\hline t1 & $12 \varnothing 6 / \mathrm{m}$ \\
\hline t2 & $12 \varnothing 6 / \mathrm{m}$ \\
\hline t3 & $12 \varnothing 6 / \mathrm{m}$ \\
\hline t4 & $8 \varnothing 10 / \mathrm{m}$ \\
\hline t5 & $16 \varnothing 10 / \mathrm{m}$ \\
\hline
\end{tabular}

\section{Conclusions}

From the above work, the following conclusions may be derived:

- Two SA-TA algorithms have been implemented for the optimization analysis of $\mathrm{PC}$ precast pedestrian bridges.

- As regards the comparison of the SA-TA procedures, they have proved efficient search algorithms for the pedestrian bridge studied, although the SA appears more efficient regarding deviation with respect to the best.

- The example presented shows the potential applicability of local search heuristic procedures for the analysis of real PC structures.

\section{References}

[1] British Standards, BS 8110-1: 1997 Structural use of concrete. Part 1: Code of practice for design and construction, British Standards, London, 1997.

[2] Cohn M.Z. and Dinovitzer A.S., Application of structural optimization. ASCE Journal of Structural Engineering, 120(2), pp 617-649, 1994.

[3] Hernández S. and Fontan A., Practical Applications of Design Optimization, WIT Press: Southampton, 2002.

[4] Fletcher R., Practical Methods of Optimization, Wiley: Chichester, 2001. 
[5] Jones M.T., Artificial Intelligence Application Programming, Charles River Media: Hingham (Massachusetts), 2003.

[6] Holland J.H., Adaptation in natural and artificial systems, University of Michigan Press: Ann Arbor, 1975.

[7] Goldberg D.E., Genetic algorithms in search, optimization and machine learning, Addison-Wesley, 1989.

[8] Glover F. and Laguna M., Tabu Search, Kluwer Academic Publishers: Boston, 1997.

[9] Yepes V. and Medina J.R. Economic heuristic optimization for the heterogeneous fleet VRPHESTW. ASCE Journal of Transportation Engineering, 132(4), pp 303-311, 2006.

[10] Jenkins W.M., Plane frame optimum design environment based on genetic algorithm, ASCE Journal of Structural Engineering, 118(11), pp. 31033112, 1992.

[11] Rajeev S. and Krisnamoorthy C.S., Discrete optimization of structures using genetic algorithms, ASCE Journal of Structural Engineering, 118(5), pp. 1233-1250, 1992

[12] Coello C.A., Christiansen A.D. and Santos F., A simple genetic algorithm for the design of reinforced concrete beams, Engineering with Computers, 13, pp. 185-196, 1997.

[13] Rajeev S. and Krisnamoorthy C.S., Genetic algorithm-based methodology for design optimization of reinforced concrete frames, Computer-Aided Civil and Infrastructure Engineering, 13, pp 63-74, 1998.

[14] Koumousis V.K. and Arsenis S.J., Genetic algorithms in optimal design of reinforced concrete members, Computer-Aided Civil and Infrastructure Engineering, 13, pp 43-52, 1998.

[15] Hrstka O., Kucerova A., Leps M. and Zeman J., A competitive comparison of different types of evolutionary algorithms, Computers and Structures, 81, pp 1979-1990, 2003.

[16] Leps M. and Sejnoha M., New approach to optimization of reinforced concrete beams, Computers and Structures, 81, pp 1957-1966, 2003.

[17] Lee C. and Ahn J., Flexural design reinforced concrete frames by genetic algorithm, ASCE Journal of Structural Engineering, 129(6), pp 762-774, 2003.

[18] Camp C.V., Pezeshk S. and Hansson H., Flexural design reinforced concrete frames using a genetic algorithm, ASCE Journal of Structural Engineering, 129(1), pp 105-115, 2003.

[19] Sahab M.G., Ashour A.F. y Toporov V.V., Cost optimisation of reinforced concrete flat slab buildings, Engineering Structures, 27, pp 313-322, 2005.

[20] Govindaraj V. and Ramasamy J.V., Optimum detailed design of reinforced concrete continuous beams using genetic algorithms, Computers and Structures, 84, pp 34-48, 2005.

[21] Gonzalez-Vidosa F., Yepes V., Alcala J., Carrera M. and Perea C., Simulated annealing optimization of walls, portal and box reinforced concrete road structures, In Proceedings of the Ninth International Conference on Computer 
Aided Optimum Design in Engineering, Skiathos (Greece), pp 175-186, 2005.

[22] Carbonell A, Martínez FJ, Yepes V, Hospitaler A and González-Vidosa F., Threshold accepting optimization of road vaults and rectangular hollow bridge piers, In Proceedings of the Tenth International Conference on Computer Aided Optimum Design in Engineering (OPTI-2007), Myrtle Beach (South Carolina, USA), pp 141-150, 2007.

[23] Yepes V, Alcalá J, Perea C and González-Vidosa F, A parametric study of optimum earth retaining walls by simulated annealing, Engineering Structures, 30(3), pp. 821-830, 2008.

[24] Perea C, Alcalá J, Yepes V, González-Vidosa F and Hospitaler A, Design of reinforced concrete bridge frames by heuristic optimization, Advances in Engineering Software, 39(8), pp. 676-688, 2008.

[25] Payá I, Yepes V, González-Vidosa F and Hospitaler A, Multiobjective optimization of reinforced concrete building frames by simulated annealing, Computer-Aided Civil and Infrastructure Engineering, 23(8), pp. 575-589, 2008.

[26] Kirkpatrick S., Gelatt C.D. and Vecchi M.P., Optimization by simulated annealing, Science, 220(4598), pp. 671-680, 1983.

[27] Medina J.R., Estimation of incident and reflected waves using simulated annealing, ASCE Journal of Waterway, Port, Coastal and Ocean Engineering, 127(4), pp. 213-221, 2001.

[28] Dueck G. and Scheuer T. Threshold accepting: A general purpose optimization algorithm superior to simulated annealing. Journal of Computation Physics, 90, pp 161-175, 1990.

[29] Marti JV, Heuristic optimization of prestressed concrete precast pedestrian bridges (in Spanish), Research Report CST/GPRC-14, Dep. Construction Engg., Un. Politécnica Valencia, January 2009.

[30] M. Fomento, IAP-98. Code about the actions to be considered for the design of road bridges (in Spanish), M. Fomento: Madrid, 1998.

[31] M. Fomento, EHE. Code of Structural Concrete (in Spanish), M. Fomento, Madrid, 1998. 